\title{
Using Literature Circles for Developing Reading Comprehension Skills
}

\author{
$\mathfrak{B y}$
}

Saad Kamel Mohammed Ahmed

A senior teacher of English

Dr.El-Sayed Mohamad Dadour

Professor of Curriculum \& TEFL Vice president for Community

Service \& Environmental

Development Affairs,

Damietta University

\author{
Dr.Hanaa El-Baz Ibrahim \\ Lecturer of Curriculum \& TEFL \\ Faculty of Education, \\ Damietta University
}


-1 - 


\title{
Using Literature Circles for Developing Reading Comprehension Skills
}

\begin{abstract}
The current study aimed at investigating the effectiveness of using literature circles strategy for developing reading comprehension skills. The sample of the study consisted of 80 students enrolled in the first year of Kafr Saad secondary School located in Damietta governorate. The sample's ages ranged between 15-16 years old. The sample was randomly selected then assigned into two intact groups: the experimental group $(\mathrm{N}=40)$ and the control group $(\mathrm{N}=40)$. The students of the experimental group received training through a proposed program based on literature circles; meanwhile the students of the control group received regular instruction. Two instruments were designed by the researchers, then used to collect data related to the experiment: (a) A checklist of EFL reading comprehension skills necessary for developing first year secondary stage students' reading, and (b) A pre-post reading comprehension skills test to measure reading comprehension skills before and after implementing the suggested treatment. The treatment was conducted during the first term of 2016 for three months. The content of the suggested program was taught in 34 sessions, (three sessions per week). Analyzing the results collected via the pre-post tests revealed mainly that that there were statistically significant differences at 0.05 level between the mean scores of the control and the experimental groups on the post- test, in favor of the latter concerning overall reading comprehension as well as each single reading comprehension sub-skill. It could be concluded that literature circle strategy is effective in developing students' reading comprehension skills. Pedagogical implications as well as suggestions for further research were provided.
\end{abstract}

Keywords: literature circles strategy, EFL Reading Comprehension skills. 


\section{Introduction}

Language is one of the most essential means of communication between communities and individuals. Anyone who wants to convey messages or feelings whether orally or in a written form should use a language. It is known that English language is considered the first international language which is used in all fields as; politics, technology, economy, formal conferences, industry, commerce, tourism, journalism and education.

Being one of the four major language skills, reading plays a decisive role in shaping students' educational future and it is more important to academic achievement than any other skill (Gisler \& Eberts, 2009, p. 1). It is one of the most important language skills since it affects all areas of one's life from early school stages to university level, and maybe to a further stage. So, it is crucial to take care of such a skill, because reading problems, like any other language problems do not vanish over time unless spending intended time and effort for solving them. Rather, they often persist and become too complicated to solve. Based on this idea, school is considered the best place to teach such a skill and solve its potential problems. Unexaggeratedly, school is considered as a factory that produces excellent readers.

The National Center for Educational Statistics [NCES], (2005, p. 2) defines reading as "an active and complex process that involves understanding written text, developing and interpreting meaning, and using meaning as appropriate to type of text, purpose and situation". Consequently, reading comprehension is essential to develop students' reading skills. Moreover, Paris and Hamilton (2008) point out that without comprehension, reading is reduced to just imitating the sounds of a language; and repeating a text simply by using memorization drills.

In the same respect, Brown $(1994$, p. 102) reports that reading comprehension has been considered as an active process rather than a passive one where the reader interacts with the text and others before, during and after the reading task. Greenberger and Padesky (1995, pp.272-281) also state that reading comprehension is the process where readers interact with a text by implementing their prior knowledge and the information found in the text.

Despite the fact that comprehension is so important to the learning process, many students find reading skill difficult. Comprehending a text is a challenging goal for teenagers as they continually struggle with reading for understanding (Edmonds, et al., 2009; Williams, 1998, 2000, as cited in Vaughn et al., 2011, p. 940). Most high school students are not prepared to read complex college-level texts. Students who comprehend at basic levels are subject to be unable to keep up with the needed skills required for high-level literacy associated with the many technological advances of the $20^{\text {th }}$ century (Bransford, Brown, \& Cocking, 1999, as cited in Murphy, Wilkinson, Soter, 
Hennessey, \& Alexander, 2009, pp. 740-741). According to Vaughn et al. (2011), skillful readers have the ability to detect the structure of the text, monitor understanding, make predictions, make their own connections to impressions and concepts, and review through words or writing (p. 941). Such approaches should be improved to maintain comprehension skills.

According to Hammoda (1999, p. 107), "most teachers conduct methods of teaching which mainly depend on memorizing rules and structures. Students are not given the chance to acquire language skills or to use language effectively". So, educators are in a real need of new strategies and techniques that interpret language not only as sentences, vocabulary, or structures, but also as a practice of thoughts and culture.

Many researchers such as Reichert (2005) and Harmer (2001) suggest that innovative concepts related to teaching reading may be required to replace the traditional ones. Among these innovative strategies is literature-circles strategy. Literature circles are a form of literary engagement in which students are placed in small groups and encouraged to read with a focus and then report on and discuss what they read, determining for themselves what is significant and why (Daniels, 1994). During discussion, each student undertakes a role that corresponds to specific cognitive tasks, thereby providing a supporting framework for the discussion. The classroom teacher offers help and support to students as they apply strategies while interacting with each other and with the text. A long-term goal of this approach is the self-regulated use of these strategies to foster comprehension (Hill, Noe, \& King, 2003). In that sense, literature circles (LC) is a teaching method in which students discuss parts of books they read at certain intervals in groups formed according to books they choose to read (Daniels, 2002).

Literature circles give students the opportunity to create connections between texts and personal experiences, monitor and take ownership or their own learning, as well as have the opportunity to listen to other group members' interpretations of the same text. Moreover, it provides students with an avenue to discuss and share thoughts and opinions, adding extended enjoyment to text reading (Zemelman, Daniels, \& Hyde, 1993, cited in Keulen, 2011).

Furthermore, literature circles give students a chance to select what to read and an opportunity to talk to each other, on a weekly basis, about a particular book. This encourages free expression of readers' opinion, and gives an opportunity to share ideas that students normally do not do in a whole group classroom setting. Research indicates not only have literature circles increased reading comprehension skills, but also this activity has encouraged students to become active listeners and risks takers while increasing their communication skills, and developing more of their thinking abilities ( Brown, 2002). 


\subsection{Background and statement of the Problem}

In spite of the importance of reading skill at the secondary stage, students suffer from weaknesses in their reading comprehension skills. This can be attributed, in the light of the researchers' experience, to the prevailing traditional methods of teaching reading. Students are rarely required to say more than a few words in response to some 'display' questions raised by the teacher. Moreover, some students lack the reading skills necessary to read long texts carefully. The Students seem to face difficulties in: deducing meaning of unfamiliar words from context; answering factual, inferential, judgmental or evaluative questions; analyzing text for setting, theme, characters; inferring mood and author's attitude or tone; making inferences about reading a text; and/or summarizing a text. In addition, students may have undesirable attitudes toward reading or the English language in general. They may be unwilling to read and comprehend. It is easy for them to answer questions based on literal levels such as identifying the main idea (skimming) and extracting information and details (Scanning). Many researchers state that students lose interest in reading and lack motivation to read in middle and high school and view reading as chore (Early, Fryer, Leckbee, \& Walton, 2004; Howerton \& Thomas, 2004). In the sense that as students enter the intermediate and middle grades their motivation to read for pleasure and their attitude toward reading begin to decline.

Accordingly, the researchers conducted a pilot study to determine how far secondary school students acquire reading comprehension skills to assure that there were serious problems related to reading comprehension in the Egyptian secondary school. This pilot study test was administered to 50 second year secondary students where five reading skills were tackled. The results of this piloting test, along with grade 10 English first term exams (2014) revealed that there was a weakness in the reading comprehension skills among secondary stage students.

To come to a closer identification of the problem, the researchers conducted a pilot study based on an informal questionnaire administered to 16 secondary stage English language teachers and supervisors (8 teachers and 8 supervisors). This questionnaire aimed at identifying the methods and techniques currently employed to develop reading comprehension skills among secondary school students. The researchers found out that students were not provided with adequate opportunities to practice reading comprehension

Major findings of the questionnaire revealed that there was no interaction between teachers and students and interaction among students themselves in reading classes. Teaching main steps in reading classes were reported to be:

\section{Pre-reading.}

Teachers ask students few revision questions about the previous lesson. 


\section{During reading.}

1. Teachers read new vocabulary and sentences aloud.

2. Teachers translate new words and write them on the blackboard

3. Students are asked to repeat after them only.

4. Teachers generate reading comprehension questions to be discussed.

5. Teachers make prediction about what will happen next in the text.

\section{Post-Reading}

This stage starts immediately after concluding the actual reading stage. In this stage, the students' focus is more on a detailed analysis of the text. That is, they used to answer comprehension such as who?, what?, where?, when? and how?

Problem of the study was further supported by the results of previous related studies in the Egyptian context such as the studies of Khalaf (2002), Darifa (2012), Abdel-Maksoud (2012), El-Arab (2012), Hassan (2013) and Ibrahim (2007) which emphasized the fact that EFL reading comprehension skills are inadequate. Thus, all the previous studies highlighted the need for adopting better teaching strategies to foster EFL secondary students' reading comprehension skills.

Hence, it is so important to carry out such a study in order to improve students' reading skills and increase their achievement through using a suggested program based on literature circles. Literature circles boost a helpful, responsible, and entertaining classroom environment where students make decisions in accordance with their own needs and interest (Burns, 1998). When students work with peers they improve their listening skills as well and become more authentic with those who make up their interesting learning community. Moreover, literature circles are controlled by students and their own visions and investigations, making reading classes significant and authentic.

In the light of the review of related literature and results of the pilot study, it could be said that the problem of the present study is represented by secondary school students' shortage in reading comprehension skills due to the lack of motivation and limited participation in classroom reading activities. Thus, the present study aims at investigating how far a program based on literature circles strategy can improve EFL reading comprehension skills among secondary school students.

\subsection{Research Questions}

The present study attempts to answer the following main question:

To what extent is the proposed program effective in developing secondary stage students' reading comprehension skills? 
This question can be divided into the following sub-questions

1. What are the basic EFL reading comprehension skills required for secondary school students?

2. To what extent do first year secondary school students master such skills?

3. What are the features of the literature circles program to develop secondary stage students' reading comprehension?

4. How far is the proposed program effective in developing first year secondary school students' EFL reading comprehension skills?

\section{Review of literature}

The term, literature circle is used to refer to an approach that incorporates reading, writing, and literature discussions in small groups. For instance, four to five students are seated close to one another, talking about a book they are reading, using text to inform, confirm, laugh, argue, and share for purposes that are largely of the students own choosing (Noe \& Johnson, 1999).

Literature circles are also called group meetings in which students are asked to get together to read, recollect, reflect, and analyze the assigned reading materials. The true intent of LC is to allow students to practice and develop the skills and strategies of good readers (Hismanoglu, 2005). They are viewed as a viable means to provide authentic or meaningful reading experiences by engaging students in reading real books (Daniels, 1994, 2002).

Literature circles are different from other kinds of group discussion; they are distinctive in that they incorporate various learning features in literary instruction. Generally, all literature circles share three basic elements: diversity, self-choice, and student initiative (Lin, 2002). Literature circles combine the principles of cooperative learning and independent reading into a group discussion. Hence, Daniels (2002, p. 18) introduced the characteristics of LCs including the following eleven key elements, each of which adds to the success of LCs. These elements deal, among other things, with: regular meetings of small groups; discussing ideas within prescribed rules; taking notes when necessary; and having the teacher as monitoring facilitator, in an enjoyable classroom environment. In addition, Sandman and Gruhler (2007) identify five key features of literature circles which include: student choice, mini-lessons, reading schedules, note-taking skills and assessment.

Literature circles can be effective for improving reading comprehension and the enjoyment of reading which could boost motivation (Whittaker, 2012, p. 221). Harvey and Goudvis (2000) and Keene and Zimmerman (1997) have identified seven comprehension strategies that may be used in literature circles. These strategies are: making connections, questioning, inferring, visualizing or using mental imagery, determining importance, synthesizing, and monitoring. 
Given the importance of literature circles strategy in developing reading comprehension skills, some researchers were interested in investigating the effectiveness of the strategy. This concern exhibited itself in conducting a number of studies to investigate the effectiveness of The Literature circles strategy. For instance, Lin (2013) aimed to explore how the implementation of literature circles could lead to the development of critical thinking skills among senior high school students and how students perceive literature circles. The classroom research approach was used to conduct the study. The participants were 37 students in the second year of senior high school. During a seven-week study, the students read seven short stories. Findings of that study revealed that there were changes in student-generated questions suggesting that the students had a slight development toward critical thinking after practicing literature circles. They added more interpretation and application to their questions. The prevalence of Why questions also showed a kind of development of critical thinking. The responses also suggested a sort of development of students' thinking in personal interpretive and critical modes. These students' perception questionnaire showed the advantages of literature circles, including improvement in language proficiency, development in cooperation, social interaction, learning behavior, attitudinal change, and thinking cultivation.

The purpose of Brown's study (2002) was to determine the effectiveness of using literature circles to improve reading comprehension skills of eighthgrade students in a middle school located in middle Georgia. A quasiexperiment was used with a random assignment to the experimental or control group. One reading class received traditional drill and classroom practice, while the other group was placed in literature circles according to the novel they chose to read. Both groups were pre-tested and post-tested and both of them were equal at the time of the pretest. During that first experiment, the results were mixed. Significant gains were made by the experimental group. Then the groups swapped instructional methods for the next reading unit. That second experiment yielded opposite results. The group that was initially introduced to literature circles did better on the pre-test for experiment 2 , as well as on the post-test, even though by that time they received traditional instruction. Both groups were heterogeneous for high, medium, and low reading abilities. The results of that research support the use of both literature circles and traditional drill and practice to improve reading comprehension skills.

Similarly, Briggs (2010) examined the use of literature circles in a third grade class. The research examined student performance on reading comprehension assessments before and after the use of literature circles. Other evidence of student learning and engagement with reading were examined. This research provides third grade teachers with literature circles activities to support the development of reading comprehension in their students. This research found that through the use of literature circles students developed better 
comprehension skills while increasing social skills that will lead to enriched learning.

Lai (2011) investigated the effects of integrating literature circles into freshmen English classes on cultivating critical thinking skills among adult Taiwanese EFL learners. In addition, that study examined, from the participants' perspective, the influence taking part in literature circles (LC) had on shaping EFL learners' thinking processes. A mixed-method approach was adopted with 57 Taiwanese freshmen studying English as a foreign language. The results of that study showed that participants' reading strategies and behaviors in both the in-class face-to-face and computer-mediated groups were positively affected after a year of participating in literature circles. Furthermore, the results of the Self-Assessment of a Critical Thinking Survey indicated that no significant difference was found between the critical thinking of the participants in the two groups. In other words, improvement was found in both groups as measured by a rise in levels of Bloom's Taxonomy. As for the results from the qualitative data, growth was found in participants' critical thinking skills in both groups. Furthermore, the results of the open-ended questionnaire indicated that a majority of the participants in that study favored literature circles and claimed that literature circles enhanced their language skills such as reading and speaking. More importantly, many participants pointed out that literature circles increased their awareness of critical thinking.

Additionally, Avci and Yuksel (2011) examined the effect of literature circles on fourth grade primary students' reading habits and comprehension skills and collected the opinions of students and teachers about that method. In that study, quantitative (pre-test and post-test designs) and qualitative (case study) methods were employed together. That study was conducted on 72 students in the fourth grade of a private school in Istanbul. The findings of such a study showed that the literature circles method improved the reading comprehension skills of students who had low level reading comprehension. It was also found out that students liked reading books by performing different tasks, discussing and cooperating with their friends over a period of time.

Finally, the purpose of Anderson 'study (2012) was to develop a comprehensive understanding of the effects of the implementation of literature circles in an ELL classroom. Literature circles were implemented each day over a nine-week period. Questionnaires were given to the students before and after the implementation of literature circles. A quasi-experimental study compared the control group to that of the treatment group. Students' perceptions of reading before and after the implementation of literature circles were analyzed through the study of the questionnaires, and standardized test scores were analyzed to monitor whether there was an increase due to the implementation of literature circles. The participants of that study were 40 ELL students in the control group and 15 students in the treatment one. The results of that study 
were that the implementation of literature circles positively affected students' perceptions of reading, and the implementation of literature circles improved standardized reading test scores.

\section{Methodology}

\subsection{Participants of the study:}

The sample of the study consisted of 80 students enrolled in the first year; of Kafr Saad secondary school located in Damietta in the academic year 2016/2017. The sample's ages ranged between 15-16 years old. The sample was randomly assigned into two intact groups, the experimental group (40) and the control group (40). The main researcher taught the experimental group by himself using the proposed program based on literature circles, whereas the control group was taught using the traditional way of instruction by the regular classroom teacher without receiving the proposed literature circles strategy.

\subsection{Hypotheses of the Study}

In the current research, the researchers intended to verify the following hypotheses:

1. There would be no a statistically significant difference between the mean scores of the experimental group and the control one in the pre-test, concerning overall EFL reading comprehension skills.

2. There would be a statistically significant difference between the mean scores of the experimental group and the control one in the post-test concerning overall EFL reading comprehension skills, in favor of the former.

3. There would be a statistically significant difference between the mean scores of the experimental group in the pre-and post-tests concerning overall EFL reading comprehension skills in favor of the latter.

\subsection{Instruments of the study}

In order to collect data related to the current study, the researchers developed and administered an EFL reading comprehension skills list and an EFL reading comprehension test.

\subsection{EFL reading comprehension skills list}

The checklist was employed to determine the most important reading comprehension skills to be developed at this particular stage. For validating the reading comprehension skills list, face validity and content validity were used. After analyzing the jury responses, the researcher selected those skills that were agreed upon at least $95 \%$ or more by the jury members. Therefore, nineteen skills were selected to be included in the present study. These skills were the 
ones that received the highest frequency according to the jury members' opinions.

\section{3 .2. The EFL Reading Comprehension Test}

A pre- post reading comprehension test was constructed and administered on research participants. It was used prior to the program implementation to make sure that students of both groups were at the same reading comprehension level before starting the experiment, and hence the progress posited to be achieved by the experimental group could be attributed to the suggested treatment. As a post-test, it was applied to investigate the effectiveness of the proposed program based on literature circle strategy in developing the selected literal, inferential, critical and creative reading comprehension skills.

The test was constructed in the light of the following resources:

1. Reviewing previous studies concerned with language tests, especially those tackling the topic of how to develop reading comprehension tests.

2. Identifying the skills to be measured by the test through the results of the checklist.

3. Some reading comprehension tests in English language designed to measure first year secondary students' level in EFL reading comprehension skills were reviewed. These tests helped in preparing and building the reading comprehension test used in the present study.

The final version of the pre - post reading comprehension test, modified after the pilot study, consisted of two reading comprehension passages followed by multiple-choice questions, open- ended questions and cloze questions. The test included 40 items that assessed the specified reading comprehension skills. The number of items allocated for each skill was selected according to each skills relative weight as estimated after analyzing the responses of a panel of jury to the reading comprehension skills checklist. The reading texts included in the final version of the test were all adapted to suit the proficiency level of Egyptian EFL first year secondary school students.

To verify the validity of the EFL reading comprehension test, face validity, content validity, internal validity, construct validity and intrinsic validity were used for estimating the validity of the reading comprehension test (RCT). The statistical findings of correlation coefficient of every item of the reading comprehension skills test indicated that the sub- EFL reading comprehension skills test ranged between (0.51-0.85) which are statistically significant at (0.05) level of confidence. These findings reveal the high internal consistency the test.

Besides, the intrinsic validity values for the four dimensions of the test ranged between $(0.86-0.89)$ with total average $(0.86)$ for the whole test. 
Hence, the validity of the pre/ post EFL reading comprehension skills was verified.

In order to estimate the reliability of the EFL reading comprehension test, the researchers used Cronbach's Alpha Coefficient in case of item deletion. Results are shown in the following table.

Table 1. The Reliability Coefficient and Intrinsic Validity of the Reading Comprehension Skills Test

\begin{tabular}{|l|c|c|}
\hline \multicolumn{1}{|c|}{ Main skill } & Alpha Cronbach's & $\begin{array}{c}\text { Intrinsic } \\
\text { Validity }\end{array}$ \\
\hline Literal comprehension & 0.76 & 0.87 \\
\hline Inferential comprehension & 0.79 & 0.89 \\
\hline Critical Comprehension & 0.77 & 0.88 \\
\hline Creative comprehension & 0.75 & 0.86 \\
\hline EFL Reading Comprehension \\
Skills
\end{tabular}

The previous table shows that the reliability coefficient of the four reading skills ranged between $(0.75-0.79)$ with total average $(0.74)$ for the whole test. These values can be trusted and means that the test was reliable. Therefore, the researchers formulated the test in its final version.

\section{a. Discrimination Coefficient:}

The researcher estimated the discrimination coefficient for every item in the test. Item discrimination coefficient, which had less than 0.2 was considered a non-discriminating item. The results showed that discrimination coefficients ranged between $(0.33-0.88)$, which means that all the items were considered acceptable or in the normal limit of discrimination according to the view point of assessment and evaluation specialists.

\section{b. Difficulty Coefficient:}

Difficulty coefficients were calculated to every item of the test using the following formula:

\section{$\mathbf{K}$}

Difficulty Coefficient $(b)=\frac{}{\mathrm{Y}+\mathrm{K}}$

Item difficulty coefficient with a value greater than 0.1 was considered a difficult one. The results showed that the difficulty coefficients ranged between (0.37- 0.83) for all the RCST items, which means that they were of medium 
difficulty, that means that each item was acceptable or in the normal limit of difficulties according to the view point of assessment and evaluation specialists. The following table shows the discrimination and difficulty coefficient for each item of the test:

Table 2. Discrimination and Difficulty coefficient for each item of the test EFL Reading Comprehension Skill

\begin{tabular}{|c|c|c|c|c|c|}
\hline $\begin{array}{l}\text { Main } \\
\text { skill }\end{array}$ & Sub-skill & $\begin{array}{l}\text { Sum of } \\
\text { question } \\
\text { degrees }\end{array}$ & $\begin{array}{c}\text { Maximum } \\
\text { question } \\
\text { degree }\end{array}$ & $\begin{array}{c}\text { Difficulty } \\
\text { coefficient }\end{array}$ & $\begin{array}{c}\text { Discrimination } \\
\text { Coefficient }\end{array}$ \\
\hline \multirow{4}{*}{ 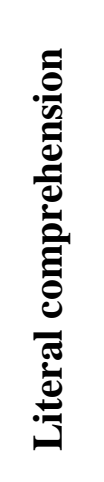 } & $\begin{array}{l}\text { Skimming the text for the gist } \\
\text { (main idea). }\end{array}$ & 33 & 60 & 0.55 & 0.88 \\
\hline & $\begin{array}{l}\text { Scanning the text for specific } \\
\text { information }\end{array}$ & 53 & 120 & 0.44 & 0.72 \\
\hline & $\begin{array}{c}\text { Understanding explicitly stated } \\
\text { information }\end{array}$ & 46 & 90 & 0.51 & 0.83 \\
\hline & Ordering the events & 88 & 240 & 0.37 & 0.33 \\
\hline \multirow{5}{*}{ 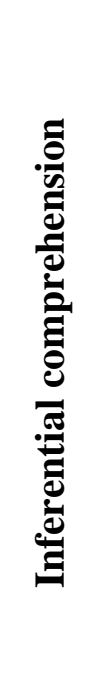 } & $\begin{array}{l}\text { Recognizing figurative } \\
\text { language }\end{array}$ & 37 & 60 & 0.62 & 0.88 \\
\hline & $\begin{array}{l}\text { Understanding references of } \\
\text { words and pronouns }\end{array}$ & 33 & 60 & 0.55 & 0.88 \\
\hline & $\begin{array}{c}\text { Inferring vocabulary in context } \\
\text {-implied meaning }\end{array}$ & 29 & 60 & 0.48 & 0.69 \\
\hline & $\begin{array}{c}\text { Drawing inferences } \\
\text { and logical conclusions }\end{array}$ & 47 & 90 & 0.52 & 0.83 \\
\hline & $\begin{array}{l}\text { Inferring cause and effect } \\
\text { relationship }\end{array}$ & 36 & 60 & 0.60 & 0.88 \\
\hline \multirow{4}{*}{ 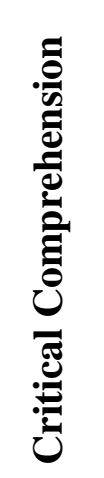 } & Expressing an opinion & 33 & 60 & 0.55 & 0.81 \\
\hline & $\begin{array}{l}\text { Forming judgment and } \\
\text { evaluation }\end{array}$ & 25 & 30 & 0.83 & 0.63 \\
\hline & $\begin{array}{l}\text { Analyzing the basic elements of } \\
\text { the short story }\end{array}$ & 76 & 180 & 0.42 & 0.42 \\
\hline & $\begin{array}{l}\text { Judging the accuracy of given } \\
\text { information }\end{array}$ & 25 & 60 & 0.42 & 0.81 \\
\hline
\end{tabular}




\begin{tabular}{|c|c|c|c|c|c|}
\hline \multirow{2}{*}{$\begin{array}{c}\text { Main } \\
\text { skill }\end{array}$} & Sub-skill & $\begin{array}{c}\text { Sum of } \\
\text { question } \\
\text { degrees }\end{array}$ & $\begin{array}{c}\text { Maximum } \\
\text { question } \\
\text { degree }\end{array}$ & $\begin{array}{c}\text { Difficulty } \\
\text { coefficient }\end{array}$ & $\begin{array}{c}\text { Discrimination } \\
\text { Coefficient }\end{array}$ \\
\hline & $\begin{array}{c}\text { Identifying the author's } \\
\text { tone/bias/viewpoint }\end{array}$ & 41 & 90 & 0.46 & 0.63 \\
\cline { 2 - 6 } & Predicting outcomes & 37 & 60 & 0.62 & 0.75 \\
\cline { 2 - 6 } & $\begin{array}{c}\text { Distinguishing between facts } \\
\text { and opinions }\end{array}$ & 54 & 90 & 0.60 & 0.71 \\
\hline \multirow{2}{*}{$\begin{array}{c}\text { Suggesting a new title for a } \\
\text { text. }\end{array}$} & 91 & 240 & 0.38 & 0.41 \\
\cline { 2 - 5 } & $\begin{array}{c}\text { Suggesting a different way to } \\
\text { solve the problem }\end{array}$ & 51 & 120 & 0.43 & 0.56 \\
\cline { 2 - 5 } & $\begin{array}{c}\text { Inventing a new course of } \\
\text { action }\end{array}$ & 91 & 240 & 0.38 & 0.42 \\
\hline
\end{tabular}

Table 2 (continued)

\subsection{The Treatment}

The main purpose of the current study was to develop the reading comprehension skills of the participants by using a proposed 34-session program based on literature circles. The experiment lasted for three months during the first semester of the academic year (2016-2017); where the proposed program was scheduled to be taught for 45 minutes within three sessions per-week. The program was taught by the main researcher, whereas the control group was taught using the traditional way of instruction by the regular classroom teacher.

The content of the proposed program were developed using authentic materials/texts which were selected from different resources. These resources included Student's Hello Reader, simplified Oliver Twist by Charles Dickens, Student's English Language Textbook Hello 6, three Fable stories and finally simplified Hamlet, English readers. The researchers selected these authentic materials/texts to attract the students' attention and challenge their cognitive domain and thinking skills, besides giving them familiar passages from their own syllabus. The texts which were selected were expository and narrative in order to be suitable for the nature of literature circles and course objectives.

At the beginning of the experiment each LC student was handled a copy of handouts of the instructional material. An introductory session was presented to explain orally a summary of the nature and purpose of the program; and to motivate the participants as well. 


\section{Results}

In order to verify research hypotheses, The Statistical Package of Social Sciences/Personal Computer (SPSS/PC) version 22 was used for statistical analysis to calculate: (a) the average (mean scores) and standard deviation, and (b) the t-test for paired samples and independent samples to compare between the experimental and control groups before and after the field study.

\subsection{Verifying the First Hypothesis}

In order to verify the first hypothesis, a t- test for independent samples was used to compare the mean scores of the two groups on the pre-test. The results of the t- test proved to be statistically consistent with the hypothesis. See table 3 which shows the mean scores, standard deviations, t- value and the level of significance of the experimental group and the control group students concerning overall EFL reading comprehension skills, in the pre assessment.

Table 3. T.Test results of the pre- test comparing the control and the experimental groups in overall reading comprehension

\begin{tabular}{|c|c|c|c|c|c|}
\hline Group & N & Mean & SD & T & P-value \\
\hline Experimental group & 30 & 20.15 & 3.72 & \multirow{2}{*}{0.45} & 0.65 \\
\hline Control group & 30 & 19.73 & 4.61 & & \\
\hline
\end{tabular}

Table (3) indicates that the mean scores of both the experimental group $(x l=20.15)$ and control group $(x 2=19.73)$ were approximately the same. From tvalue for independent groups (0.45). It is obvious that there was no statistically significant difference between the mean scores of the experimental group and the control one in the pre-test, concerning overall EFL reading comprehension skills. Hence, it could be said that both groups were homogeneous and almost at the same level of comprehension performance; and therefore any variance between the two groups that may occur after the implementation of the program will be attributed to it.

The following figure illustrates these results

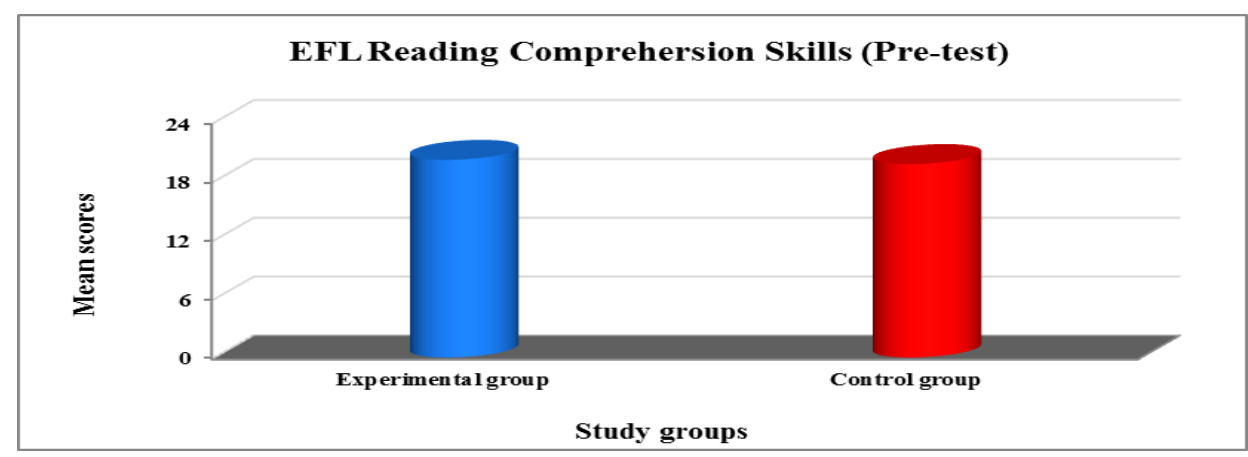

Figure 1. Comparison of the pre- test mean scores of the control and experimental groups in overall reading comprehension 


\subsection{Verifying the Second Hypothesis}

In order to verify the second hypothesis, a t- test for independent samples was used to compare the mean scores of the two groups in the post-test. The results of the t- test proved to be statistically consistent with this hypothesis. See table 4 which elaborate the results related to this hypothesis.

Table 4. T- Test results of the post- test comparing the control and the experimental groups in overall reading comprehension

\begin{tabular}{|c|c|c|c|c|c|}
\hline Group & N & Mean & SD & T & P-value \\
\cline { 1 - 4 } Experimental group & 30 & 53.15 & 3.98 & \multirow{2}{*}{23.97} & \multirow{2}{*}{0.001} \\
\cline { 1 - 4 } Control group & 30 & 34.15 & 3.05 & & \\
\hline
\end{tabular}

Table (4) shows that there is a statistically significant difference between the mean scores of the experimental group and the control one in the post-test concerning overall EFL reading comprehension skills, in favor of the former. Tvalue" is (23.97) which is significant at level of (0.01). Thus, the second hypothesis was apparently verified.

The experimental group students' significant progress in their overall reading comprehension compared to the control group students' performance on the post-test can be illustrated in figure 2

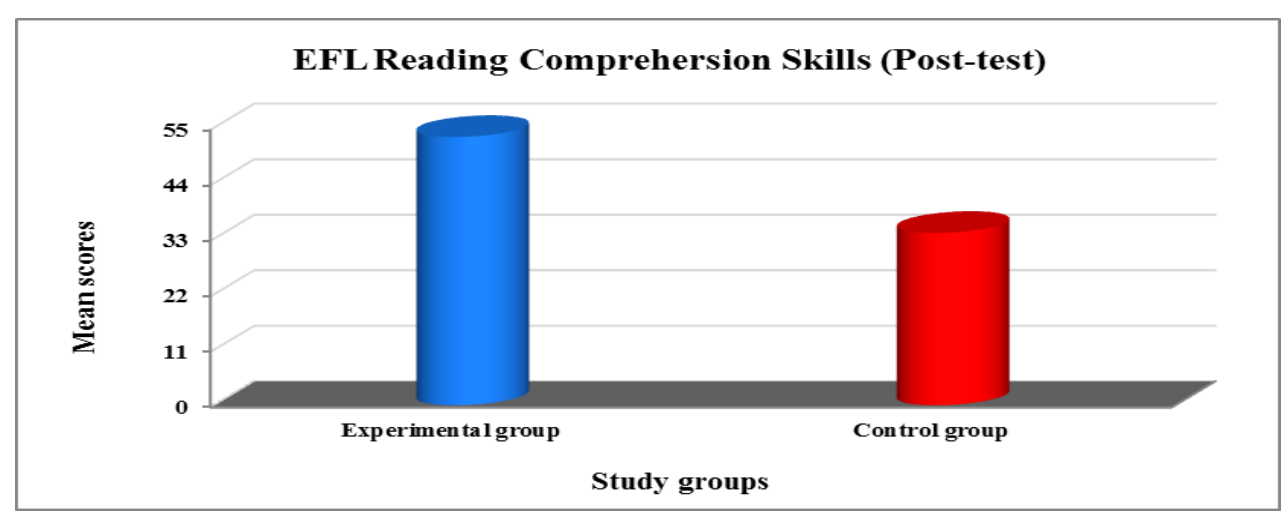

Figure 2. Comparison of the post- test mean scores of the control and experimental groups in overall reading comprehension

\subsection{Verifying the Third Hypothesis}

In order to verify the third hypothesis and determine the relative extent of change fostered by the implementation of the proposed program from the pretest to the post-test regarding the experimental group, a paired samples $t \mathrm{t}$-test was used. This t-test aimed at comparing the mean scores of the experimental group in the pre- test and the post- test in overall reading comprehension. The results of the t- test proved to be statistically consistent with the hypothesis. For visual representation of the results, see table 5. 
Table 5. T-test results comparing the pre- test vs. post- test means for the experimental group in overall reading comprehension

\begin{tabular}{|c|c|c|c|c|c|}
\hline Test & $\mathbf{N}$ & Mean & SD & T & P-value \\
\cline { 1 - 4 } post-test & \multirow{2}{*}{40} & 53.15 & 3.98 & \multirow{2}{*}{39.88} & 0.001 \\
\cline { 1 - 1 } Pre-test & & 20.15 & 3.72 & & \\
\hline
\end{tabular}

Table (5) indicates that there was a statistically significant difference between the mean scores of the experimental group in the pre-and post-tests concerning overall EFL reading comprehension skills in favor of the latter. The estimated t- value was (39.88). Thus, it can be obviously said that the t-test results prove to be statistically consistent with the hypothesis. Therefore, the third hypothesis was confirmed.

The following figure illustrates the experimental group students' significant growth in overall reading comprehension after the program application as compared to their overall reading comprehension performance on the pre- test.

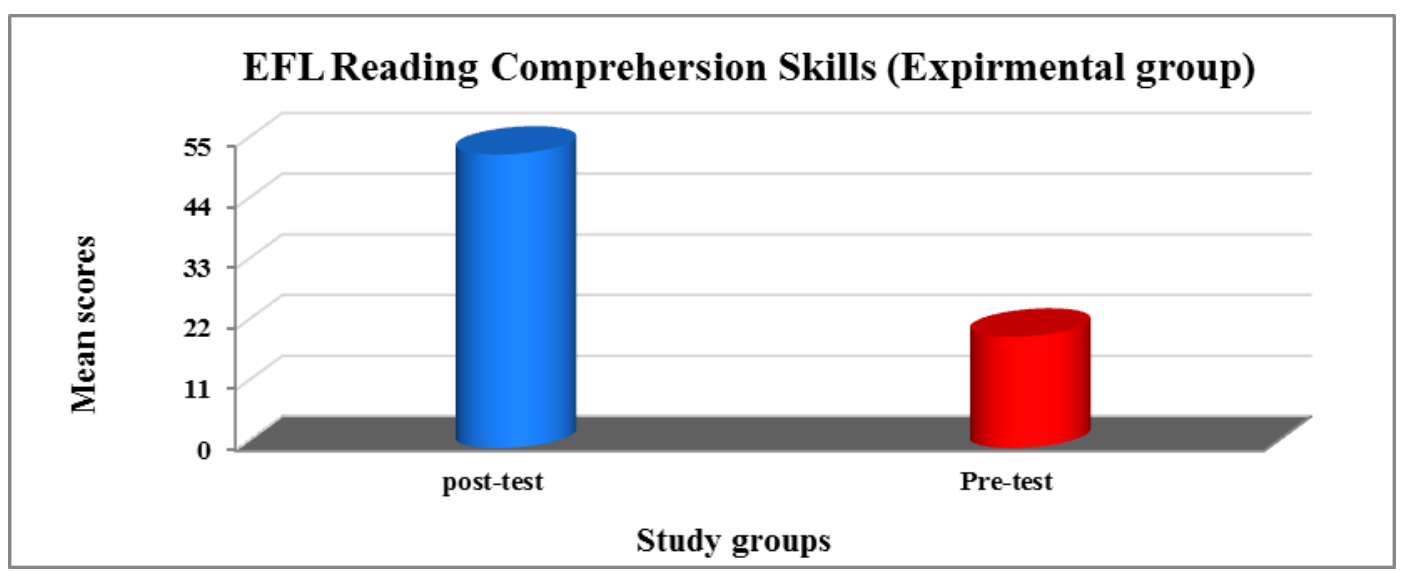

Figure 3. Comparison of the pre- test vs. post- test means for the experimental group in overall reading comprehension

\subsection{The effect strength of the treatment:}

In order to make sure that the results obtained from the t- test were reliable; and to measure the effectiveness of the proposed program on students' reading comprehension skills, its effect size on students' reading comprehension skills was calculated according to the following formula as suggested by Dunlap (1994):

$\boldsymbol{\eta}^{2}=\frac{\mathbf{t}^{2}}{\mathbf{t}^{2}+\mathrm{df}}$

" $\eta$ " is the total effect size of the strategy.

" $t$ " is the value of t-test.

"d.f" is the degree of freedom. 
Effect sizes can be of any magnitude. Effect sizes less than or equal to 0.20 are generally viewed as small, effect sizes equal to 0.50 are generally interpreted as having medium effects, and effect sizes greater than or equal to 0.80 are considered large (Cohen, 1988).

Becker (2000, p.3) states that the referential frameworks for interpreting the effect size value could be as follows:

Table 6. Interpretation of Effect Size

\begin{tabular}{|c|c|}
\hline EFFECT SIZE & INTERPRETATION \\
\hline From 0.2 to less than 0.5 & Small \\
\hline From 0.5 to less than 0.8 & Medium \\
\hline 0.8 or more & Large \\
\hline
\end{tabular}

Table 7. The effect strength of the treatment ( $\boldsymbol{\eta}^{2}$ value) for overall reading comprehension and its sub-skills

\begin{tabular}{|l|c|c|c|}
\hline \multicolumn{1}{|c|}{ Main skill } & Df & T & Eta square \\
\hline Literal comprehension & 39 & 25.22 & 0.942 \\
\hline Inferential comprehension & 39 & 25.99 & 0.945 \\
\hline Critical Comprehension & 39 & 26.26 & 0.946 \\
\hline Creative comprehension & 39 & 17.70 & 0.889 \\
\hline EFL Reading Comprehension Skills & $\mathbf{3 9}$ & $\mathbf{3 9 . 8 8}$ & $\mathbf{0 . 9 7 6}$ \\
\hline
\end{tabular}

As shown in table 7, the calculated effect size value of the proposed program on the experimental group students' overall reading comprehension was (0.976). This value refers to the fact that the effect size of the independent variable (Literature Circles) on the dependent variable (Reading Comprehension) was great; and this led to improving students' scores after administering the program. Therefore, it can be said that the proposed program had a large effect on the experimental group students' overall reading comprehension in the post-test as compared to that of the control group students who received regular instruction.

Figure 4 illustrates the effectiveness of using literature circles in improving secondary stage students' English reading comprehension skills. It shows the $\left(\boldsymbol{\eta}^{2}\right)$ value of overall reading comprehension skills in a visual form. 


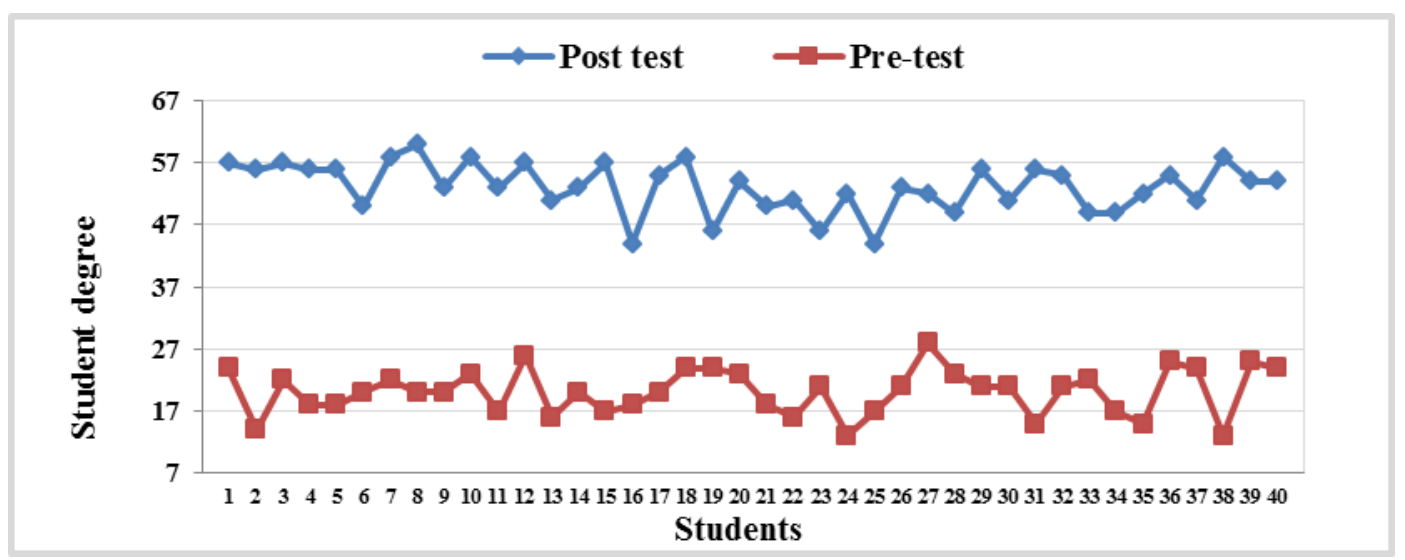

Figure 4. The effect strength of the treatment ( $\boldsymbol{\eta}^{2}$ value) for overall reading comprehension and its sub-skills

\section{Discussion and Conclusion}

The main purpose of the present study was to develop EFL reading comprehension skills through literature circles using a variety of activities and strategies that were offered to the experimental group. The findings showed that the experimental group students have improved in EFL reading comprehension skills more than the control group students in the post application of the EFL reading comprehension test compared to the pre-test. This progress is caused by the effect of using the literature circles program. This proves that literature circles are statistically and educationally significant in developing student's reading comprehension skills. Thus, in the light of the post- test results of the present study, the researchers could safely say that the program implemented was effective and accounted for some factors that might have helped the experimental group students' progress in overall reading comprehension performance and in each reading comprehension sub-skill:

First, the first element in the program was mainly dependent on three integrations. The integration and interaction between reading comprehension, attitude toward studying English and literature circles which improved the students' reading comprehension skills. Accordingly, the students participated in interactive literature circles while comprehending their texts. Besides, every group member had a literature circle role task or responsibility to do. All students were trained to use each reading comprehension skill properly, and were allowed to discuss and share ideas; they were able to understand any literary work successfully. As an outcome, students began to think on a deeper level about what they are reading, share their thoughts, feelings, and questions in a small non-threatening atmosphere.

The second element that might have been responsible for developing the participants' reading comprehension skills can be attributed to literature circle role tasks; which could be said to be the most important element in enhancing reading comprehension skills. These roles could cover literary elements of the 
short story and play and were suitable for the objectives of the study. Each role had a clear description of the tasks that the students were expected to do. These roles were rotated each time students started reading a new short story to give all students the chance to practice the different roles. For example, the discussion leader kept the discussion flowing and opened the discussion with a few openended questions for his/her group. Another partner was the summarizer who forced them to read the story a number of times in order to pick up the most important points to present in their summary. Also, the creative connector was supposed to find connections between the text and real world in which classmates lived; e.g. , make connections between thoughts, feelings and/or actions of characters in the story and/or play. Moreover, there were other roles like passage person, word master and culture collector to be acted by the participants of the study. The word master role was to help the students choose only five words which he/she believed to be the most important words found in a given story. Furthermore, the culture collector was like the connector he/she looked at the story and notes both differences and similarities between the culture represented in the story and the classmates' culture. The passage person's role seemed to be like that of the word master where he/she just helped colleagues to find the mood of the passage and identify whether they were funny, important, or confusing, and so on. In that sense, it could be said that the results related to the second element are consistent with the results of other studies such as the studies of Daniels, (2002), Robb (2000), O'Brien (2007) and Ferguson and Kern (2012).

The third element is related to the three learning stages; i.e., pre-reading stage, during/while reading stage, and post-reading stage. At the pre - reading stage, the students took notes for five minutes before beginning to discuss the main idea to understand a novel and commented on its title. It was used to activate students' background knowledge and connect what they already know with what they are learning in school. Also, in during or while reading stage, the students reread some passage carefully to deal with the text as a whole. The students were also trained in questioning skills so that they could ask themselves questions on the significant points of a text. For example, they could ask questions about the main idea, the supporting details, or the conclusion. Finally, in the post-reading stage, the students were encouraged to answer comprehension questions, explain the characters, choose the important vocabulary and/or get the main idea with supporting details. At the end of each group discussion in class, every member put these answers into the storage system (Portfolios) as the basis for each group further discussion. This stage was used also to help students interpret, analyze and deepen their understanding. It helped the students to solidify and remember ideas presented in the text. It could be said that the results related to the third element are consistent with those of Abd El-Rahman (2010), Mera (1999), Grabe and Stoller (2002). 
Fourth, group meetings, natural conversation about books and rotation of roles allowed the students to make choices about their learning. The instructor researcher did not assign roles for the students and left this matter for the students themselves to identify them. In the sense that each one chose the role he/she saw fit. The members of each group exchanged the roles they undertook before, the discussion leader became a summarizer, and the word master became a connector, and so on. Eventually at the end, all members were able to practise all roles. Thus, a choice led the students to get engaged deeply in the task, taught them self-reliance, and gave them an opportunity for guided-decision making. Results related to this dimension cope with the study of Peralta-Nash and Duch (2000), Noll (1994) and Burns (1998).

Hence, it is clear from the discussion so far, that the proposed literature circles program was valuable in developing secondary stage students' reading comprehension skills. The results reported in the current study coincide with those of previous studies such as Brown (2002), Avci and Yuksel (2011), Anderson (2012), Hamilton (2013), Lai (2011), Maraccini (2011), Marshall (2006), Medrano (2013), Tugman (2010), Wilfong's (2009), Day, Spiegel, McLellan, and Brown (2002) and Jodi (2005) which confirm the efficacy of literature circles program in developing reading comprehension.

On the basis of the results of the present study, a persistent recommendation needs to be put into consideration when teaching reading comprehension. It is highly suggested that, curriculum designers, decision makers at the ministry of education, professors at colleges of education, and EFL educators, have to reconsider textbooks, programs, and classroom practices in the light of the importance of literature circles as elaborated in the present study. Also, further research may be suggested to be conducted to investigate the effectiveness of using literature circles, in various levels of EFL classes, on developing other language skills and/or aspects. 


\section{References}

Abd El- Rahman, S.A. (2010). The Effect of Using Semantic Mapping and K.W.L. Strategies on Developing EFL Primary School Students' Reading Comprehension Skill. Unpublished master's thesis, Zagazig University.

Abdel-Maksoud, M. (2012). The Effectiveness of the Transactional Teaching Approach in Developing EEL Strategic Reading and Reading Comprehension Skills Among Secondary School Students. Unpublished doctoral dissertation, Faculty of Education, Benha University.

Anderson, A.R. (2012). Implementing Literature Circles: AN Experimental Study in an English language Learners' Classroom. Doctor of Philosophy, School of Education, Capella University. Retrieved July 8, 2015 from: ProQuest Dissertation and Theses Database (UMI No. 3523558).

Avci, S., \& Yuksel, A. (2011). Cognitive and Affective Contributions of the Literature Circles Method on the Acquisition of Reading Habits and Comprehension Skills in Primary Level Students. Educational Sciences: Theory and Practice, 11(3), 1295-1300. DOI: 10.1080/19388070902947352.

Becker, L. A. (2000). Effect size calculators. Retrieved October 22, 2016, from: http//: www.uccs.edu/faculty/lbecker/.

Bielby, N. (1999). Teaching reading at key stage 2, Stanley Thornes Publisher, UK.

Brabham, E. G., \& Villaume, S. K. (2000). Questions and answers continuing Conversations about literature circles. The Reading Teacher, 5 (3), 278280.

Briggs,S.R.(2010). Using Literature Circles to Increase Reading Comprehension in Third Grade Elementary Students. Master of Science in Education, School of Education and Counseling Psychology, Dominican University of California. Retrieved February 29, 2014 from: http://eric.ed.gov/?id=ED511091.

Brown, H. D. (1994). Principles of Language Learning and Teaching. Englewood Cliffs, N.J: Prentice Hall.

Brown, B. A. (2002). Literature circles in action in the middle school classroom. Georgia College and State University. (ERIC Document Reproduction Service No. ED 478458).

Burns, B. (1998). Changing the classroom climate with literature circles. Journal of Adolescent \& Adult Literacy: Navigating New Literacies, 42, 
124-129. Retrieved June 25, 2015 from: Academic Search Premier database.

Byrd, D. E. (2002). An examination of how adult developmental reading students socially construct meaning while engaged in literature circles. (Doctoral dissertation, the University of Texas at Austin, 2002). Dissertation Abstracts International, 54, (2), 151. (UMI No. 3108477).

Cohen, J. (1988). Statistical power analysis for the behavioral sciences (2nd edition). Hillsdale, NJ: Lawrence Erlbaum Associates.

Daniels, H. (1994). Literature circles: Voice and choice in the student-centered classroom. York, ME: Stenhouse.

Daniels, H. (2002). Literature circles: Voice and choice in book clubs reading groups. Portland, ME: Stenhouse.

Darifa, D.S.(2012).The Effectiveness of PQRST Strategy in Developing Some EFL Reading Comprehension and Study Skills among Secondary School Student. Unpublished mater's thesis, Faculty of Education, Minufiya University.

Day, J., Spiegel, D., McLellan, J., \& Brown, V. (2002). Moving forward with literature circles. New York, NY: Scholastic.

Dunlap, W. P. (1994). Generalizing the common language effect size indicator to bivariate normal correlations. Psychological Bulletin, 116, 509-511. Google Scholar

Early, M., Fryer, R., Leckbee, J., \& Walton, B. H. (2004). What activity has been most effective in assisting high school students to read successfully. English Journal, 93, 20-24.

El-Arab, M.H. (2012). The Effectiveness of Extended Reading for Enhancing EFL Reading Comprehension and Vocabulary Acquisition of Secondary School Students. Unpublished master's thesis, Faculty of Education, Tanta University.

Ferguson, L., \& Kern, D. (2012). Re-visioning literature circles: Incorporating comprehension strategy instruction in student-led discussions. The NERA Journal, 47 (2), 23-30.

Gisler, P., \& Eberts, M. (2009). Top ten ways to improve reading skills. Retrieved June 29, 2015 from: http://school.familyeducation.com/top-10ways/improve-reading-skills/38329.html.

Grabe, W., \& Stoller, F. L. (2002). Teaching and researching reading. Harlow, England: Pearson Education. 
Greenberger, D., \& Padesky, C. (1995). Mind over mood: Change how you feel by changing the way you think. New Yorkm NY: Guilford Press.

Hamilton, T. (2013). An Exploration of the Influences of Literature Circles on Secondary Student Reading. Doctor of Education , Faculty of Education, Lindenwood University. Retrieved March 19, 2014 from: http://gradworks.umi.com/36/01/3601189.html.

Hamouda, Z. (1999). Specific Instructional Competencies for English Language Teachers at the Secondary Stage in Gaza Governorates. Unpublished master's thesis, Gaza, Al- Azher University.

Harmer, J. (2001). The practice of English language teaching, (3rd edition), Pearson Education, England: Essex.

Harvey, S., \& Goudvis, A. (2000). Strategies that work. Teaching comprehension to enhance understanding. Portland, Maine: Stenhouse Publishers.

Hassan,H.M.(2013).The Effectiveness of Audio-Assisted Reading Strategy on Enhancing EFL Prep Students' Listening and Reading Comprehension. Unpublished master's thesis, Faculty of Education, Mansoura University.

Hill, B., Noe, K., \& King, J. (2003). Literature circles in the middle school: One teacher's journey. Norwood, MA: Christopher-Gordon.

Hismanoglu, M. (2005).Teaching English through Literature. Journal of Language and Linguistic Studies, 1(1), 53-66. Retrieved October 22, 2015, from: http://www.jlls.org/issues/volume1/No.1/ murathimanoglu.pdf.

Howerton, D., \& Thomas, C. (2004). Help for high school students who still can't read. English Journal, 93 (5), 77-82.

Ibrahem, S. A. (2007). Training program in learning metacognitive strategies in English to improve reading comprehension for low- achievers in preparatory school. Unpublished master's thesis, Faculty of Education, Ain Shams University.

Jodi, M. (2005). The effects of participation in literature circles on reading comprehension. (Doctoral dissertation, University of Miami, 2005). Dissertation Abstracts International, 67(04), 101.

Keene, E. O. \& Zimmerman, S. (1997). Mosaic of thought: teaching comprehension in a reader's workshop. Portsmouth, NH: Heinemann.

Keulen, B.J. (2011). Literature Circles: Comprehension and Engagement Effects of Literature Circles on Comprehension and Engagement. Unpublished master's thesis, Southwest Minnesota State University 
Education Department. Retrieved July 9, 2015 from: http://www.k8acesscenter.org/training_resources/udl/diffinstruction.asp.

Khalaf, H. E. (2002). The effectiveness of pre-reading for developing background knowledge in EFL preparatory school students' reading comprehension. Unpublished master's thesis, Damietta Faculty of Education, Mansoura University.

Lai,C.F.(2011). Cultivating Critical Thinking through Integrating Literature Circles into EFL Freshman English Classes. Master of Arts, Faculty of the Department of Foreign Languages and Literature, Tunghai University. Retrieved April 19, 2015 from: http://thuir.thu.edu.tw/handle/310901/10965?locale=en-US.

Lin, C. (2002). Literature Circles. ERIC Document Reproduction Service No. ED 469925). Retrieved April 10, 2015 from: http://files.eric.ed.gov/fulltext/ED469925.pdf

Lin,C.(2013).Using Literature Circles to Develop Critical Thinking Skills in a Senior High EFL Classroom in Taiwan, master's thesis, National Chengchi University.

Maraccini, B. J.(2011). Teacher Perceptions of the Use of Literature Circles and Student Engagement in Reading. Doctor of Education, Piedmont College School of Education, Florida Atlantic University. Retreived December 10, 2015 from: http://gradworks.umi.com/35/18/3518832.html.

Marshall, J.C. (2006). The Effects of Participation in Literature Circles on Reading Comprehension. Doctor of Philosophy, University of Miami, Coral Gables, Florida. Retreived July 10, 2014 from: $\mathrm{http} / / /$ scholarlyrepository.miami.edu/cgi/viewcontent.cgi?article $=1049 \& \mathrm{c}$ ontext=oa_dissertations

Medrano, E. D. (2013). An Investigation of Literature Circles as a Means to Promote Reading Comprehension. Doctor of Philosophy, Faculty of Texas Tech University. Retrieved January 9, 2014 from:https://repositories.tdl.org/ttu-ir/handle/2346/50624.

Mera, R. (1999). "Reading in Recent ELT Course Book.” ELT Journal, 51 (1), 13-21.

Murphy, P. K., Wilkinson, I. A. G., Soter, A. O., Hennessey, M. N., \& Alexander, J. F. (2009). Examining the effects of classroom discussion on students' high-level comprehension of text: A meta-analysis. Journal of Educational Psychology, 101, 740-764.

National Center for Educational Statistics. (2005). 2009 NAEP reading framework. Washington DC: Author. 
Noe, K. L. S., \& Johnson, N. J. (1999). Getting Started With Literature Circles. Norwood, MA: Christopher-Gordon.

Noll, E. (1994). Social issues and literature circles with adolescents. Journal of Reading, 38(2), 88-93.

O'Brien, C. (2007). Using collaborative reading groups to accommodate diverse learning and behavior needs in the general education classroom. Beyond Behavior, 16 (3), 7-15.

Paris, S.G., \& Hamilton, E.E. (2008). The development of children's reading comprehension. In Israel, S. E, \& Duffy, G., G. (Eds.). Handbook of research on reading comprehension (pp. 32-53). Manwah, NJ: Erlbaum.

Peralta - Nash, C., \& Dutch, J.A. (2000). Literature circles: Creating an environment for choice. Primary Voices K-6-, 8 (4), 29-27.

Reichert, R. (2005). Scientific Discovery Learning with Computer Simulations of Conceptual Domains of learning. Retreived May 14, 2015 from: www.elearning-reviews.org/publications/270 HTML.

Robb, L. (2000). Teaching reading in middle school: A strategic approach to teaching reading that improves comprehension and thinking. New York, NY: Scholastic Professional Books.

Sandmann, A., \& Gruhler, D. (2007). Reading is thinking. International Journal of Learning, 13(10;10), 105-113. Retrieved November 17, 2015, from: http://search.ebscohost.com/login.aspx?direct=true \&db=ehh\&AN=24953 $882 \&$ site $=$ e host-live.

Tugman, H. (2010). Literature Discussion Groups and Reading Comprehension. Unpublished master's thesis, Northern Michigan University. Retrieved June 24, 2016 from:https://www.nmu.edu/sites/DrupalEducation/files/UserFiles/Files/Pr eDrupal/SiteSections/Students/GradPapers/Projects/Tugman_Holly__MP. pdf.

Vaughn, S., Klingner, J. K., Swanson, E. A., Boardman, A. G., Roberts, G., Mohammed, S. S., \& Stillman-Spisak, S. J. (2011). Efficacy of collaborative strategic reading with middle school students. American Educational Research Journal, 48 (4), 938-964.

Whittaker, C. R. (2012). Integrating literature circles into a cotaught inclusive classroom. Intervention in School and Clinic, 47(4), 214-223.

Wilfong, L. G. (2009). Textmasters: Bringing literature circles to textbook reading across the curriculum. Journal of Adolescent \& Adult Literacy, 53(2), 164-171. 